\title{
Women's experiences of safety apps for sexualized violence: a narrative scoping review
}

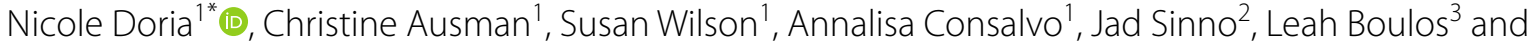 \\ Matthew Numer ${ }^{1}$
}

\begin{abstract}
Background: Sexualized violence against women is a significant human rights problem worldwide. Safety apps have the capacity to provide women with resources to prevent or respond to experiences of sexualized violence.

Methods: The aim of the following study was to review the scope of the literature on women's experiences of safety apps related to sexualized violence. The databases Embase, MEDLINE, PsycINFO, and Scopus were systematically searched, and seven studies were included in this review.
\end{abstract}

Results: Thematic analysis identified the following themes in the literature: (1) security; (2) accessibility; and (3) knowledge.

Conclusion: The gaps in the literature are identified and implications and recommendations for future research is discussed.

Keywords: Sexualized violence, Safety apps, Scoping review

\section{Background}

The high rate of sexualized violence against women is an urgent public health issue and a significant human rights problem [9]. Although this is well known, global prevalence of sexualized violence is difficult to determine as there is not a universal understanding or measurement of what constitutes sexualized violence [36]. Further, only an estimated $32-35 \%$ of incidents of sexualized violence in the United States are reported to police $[66,67]$. In $2018,652,676$ women reported being raped or sexually assaulted nation-wide in the United States [62]. Canadian data suggests even lower reporting rates of sexual assault, with only $5 \%$ reported to police [23, 24]. Self-reported data from the 2014 General Social Survey (GSS) on

*Correspondence: Nicole.doria@dal.ca

1 Dalhousie University, 6299 South St, Halifax, NS B3H 4R2, USA

Full list of author information is available at the end of the article
Canadians' Safety (Victimization) shows that there were 22 incidents of sexual assault for every 1,000 Canadians aged 15 and older, which represented approximately 636,000 incidents of sexual assault [23]. In the United Kingdom, the Crime Survey for England and Wales estimated that $20 \%$ of women experience some type of sexual assault after the age of 16 , which is equivalent to 3.4 million female victims [49]. Sexualized violence, however, is a broad term that encompasses much more than sexual assault and rape. Sexualized violence includes any unwanted sexual contact that targets sexuality and is physical and/or psychological in nature, including but not limited to sexual abuse, sexual assault, rape, sexual harassment, stalking, indecent/sexualized exposure, degrading sexual imagery, sharing sexual photographs without permission, and/or unwanted comments or jokes [71, 76]. Although anyone can experience sexualized violence, women are primarily the victims and are most 
likely experience more severe forms of violence, whereas men are typically the perpetrators $[14,65]$. Globally, one in three women experience physical and/or sexualized violence in their lifetime, mostly perpetrated by a current or former intimate partner, and six percent of women experience sexualized violence from someone other than an intimate partner $[69,76]$.

\section{Marginalized Populations}

According to the Canadian census, individuals who are young, female, Indigenous, and/or a gender or sexual minority are at greater risk for experiencing sexual assault than the general population [23]. Similar trends are noted in the United States, where a study from Colorado revealed that bisexual women are more than twice as likely to experience sexualized violence compared to straight identifying women [43]. The authors also found that $26 \%$ of transgendered participants have experienced sexualized violence and that their gender identity was the motivating factor for the assault [43]. Further, a 2018 review of the literature on technology-facilitated sexualized violence reported that women, as well as, lesbian, gay, bi-sexual, trans, and intersex individuals are at an increased risk of being the targets of online abuse [38]. These findings suggest that members of the sexual and gender diverse community are at a higher risk for experiencing sexualized violence, however, further research is needed in this area $[38,48]$.

\section{Health Outcomes and Traditional Resources}

The negative health outcomes associated with physical sexual assault are well known and include poorer selfrated health, exacerbated psychological distress, and post-traumatic stress disorder (PTSD) [3, 19, 41, 53, 61, 78]. Literature that focuses on the health outcomes associated with other forms of sexualized violence, however, is scarce $[50,56,63]$. A recent Australian study found that women's experiences of sexualized violence were most commonly public harassment, flashing, unwanted groping, or being coerced into consenting to sex [65]. These women were at an elevated risk for having anxiety, depression, and PTSD as compared to women who did not experience sexualized violence [65]. Another study reported that one-third of women who experienced sexualized violence were later diagnosed with PTSD [47]. Negative mental health outcomes have been found to interfere with the victim's physical functioning and interpersonal relationships $[7,8,31,68]$.

A variety of prevention initiatives, supports, and resources exist that aim to increase safety for women, reduce incidents of sexualized violence, and help offset the worsened health outcomes. Some examples include, educational campaigns, medico-legal services, specific training for healthcare professionals, prophylaxis for HIV infection, and centres that provide trauma-informed care [75]. Unfortunately, these initiatives and resources are often limited to high-income and resource-rich settings [76]. Further, as sexualized violence continues to rise world-wide, there is reason to believe that the current measures to address sexualized violence are insufficient (UN Women, 2019). In the majority of countries with available data, less than $40 \%$ of women who experienced violence sought help of any sort [70]. Among women who did seek help, most reached out to family and friends instead of formal institutions, and less than $10 \%$ of women sought help from the police [70]. These statistics demonstrate a need for safe, accessible, affordable, and comprehensive resources that aim to prevent sexualized violence against women and support women who have experienced sexualized violence.

\section{Mobile Technology and Safety Apps}

In today's digital age, mobile technology presents a unique opportunity to deliver improved sexualized violence interventions and resources [34]. Research shows that $95 \%$ of adults between the ages of 18 and 34 in the United States own a mobile phone [60]. Further, mobile technologies as sophisticated as smartphones are widely used around the world: $95 \%$ in South Korea, $88 \%$ in Israel, $81 \%$ in Australia, $80 \%$ in Spain, with a median worldwide ownership of smartphone technology of 76\% [59]. The extant literature has primarily focused on the ways that mobile apps can be used for health and fitness $[1,15,16]$. There has recently, however, been interest in discovering the potential of using smartphone technology to help enhance women's safety.

A recent review on the role of emerging technologies regarding women's safety found that smartphones were the most commonly discussed protective technology in the literature (37.2\% mobile phones, $18.8 \%$ apps) [20]. Smartphones can be used to call for help in emergencies, film violence incidents/injuries, retain threatening text messages, and use apps to contact support networks [20]. Another study found that $62.9 \%$ of college students would consider downloading a personal safety app, and even more students would consider doing so if the app contained a tracking feature [46]. Women were also found to be more likely than men to download a safety app with tracking features to increase their sense of security and reassurance [46]. Overall, the proliferation of technological solutions for sexualized violence such as signal-/alarm-emitting wearables and apps have surged in recent years [74].

Specific to sexualized violence, qualitative evidence shows that technology can provide access to information and services, strengthen support networks, and support 
sexualized violence victims in their safety and escape planning [77]. An Australian review found that safety apps for public stranger violence focused mainly on location-based services, personal alarms, and crowd-sourced data [45]. This review identified MySafetyPin, Saven, and My Keeper as useful safety apps allowing users to identify dangerous areas, and the Women Safety Totem SOS app for providing information to help reduce the likelihood of being a target for violence and tips on how to handle violence (e.g., self-defence information) [45]. Although there are several studies that have explored safety apps regarding sexualized violence, a preliminary search for existing reviews and protocols in MEDLINE, PROSPERO, and Open Science Framework in January 2020 revealed that the findings regarding women's experiences and perceptions of these apps has not been comprehensively reviewed. Therefore, the research question for this scoping review was: What is the scope of the literature on women's experiences of safety apps in relation to sexualized violence?

\section{Method}

A scoping review method was chosen to comprehensively review the published literature on women's experiences using safety apps related to sexualized violence [5]. The aim was to map the extant literature and research gaps on the experiences of women who use sexualized violence related safety apps, including the barriers of using such apps [5]. This scoping review employed a systematic methodology guided by the Arksey and O'Malley
[5] framework. This framework includes identifying the research question, identifying relevant studies, selecting relevant studies, charting the data, and collating and summarizing the findings [5]. Critical appraisal was not conducted, as the purpose of a scoping review is to provide an overall picture of a body of evidence on a topic, and not to assess quality and rigour [51].

\section{Identifying Relevant Studies}

The literature search for this scoping review was conducted in January 2020. The following electronic databases were searched: MEDLINE All (Ovid), Embase (Elsevier Embase.com), PsycINFO (EBSCOhost), and Scopus (Elsevier Scopus.com). Our search strategy was developed in consultation with a medical librarian at the Maritime SPOR SUPPORT Unit (LB). The search strategy was designed in MEDLINE All and Scopus between January 21 and 23, 2020, and tested using a small set of relevant articles previously identified by the review team [12, 18, 33, 74]. Once finalized, the MEDLINE All and Scopus searches were then translated to the other databases (Embase and PsycINFO) according to the controlled vocabulary and search syntax requirements of each database. No language limits or other published search filters were applied, but an ad hoc filter was developed to limit studies to those related to women. The MEDLINE All search strategy can be seen in Table 1, and translations of the search to all other databases can be found in Appendix A. Grey literature searching was not conducted separately, but any grey literature indexed in

Table 1 Ovid MEDLINE All search strategy, subsequently translated to other databases and executed on January 23, 2020

\begin{tabular}{|c|c|}
\hline 1 & exp Intimate Partner Violence/ \\
\hline 2 & exp Sex Offenses/ \\
\hline 3 & (anti-abuse or anti-assault or anti-harassment or anti-rape or anti-victim* or anti-violence).ti,ab,kw,kf. \\
\hline 4 & $\begin{array}{l}\text { ((dating or domestic or gender* or partner* or relationship* or wom\#n or sex*) adj2 (abuse* or } \\
\text { assault }{ }^{*} \text { or violence)).ti,ab,kw,kf. }\end{array}$ \\
\hline 5 & (intimate partner violence or ipv).ti,ab,kw,kf. \\
\hline 6 & (rape or rapes or raped or rapist* or raping).ti,ab,kw,kf. \\
\hline 7 & (sex* adj2 coerc*).ti,ab,kw,kf. \\
\hline 8 & (sex* adj2 (force* or unwanted or unwelcome)).ti,ab,kw,kf. \\
\hline 9 & (sex* adj2 harass*).ti,ab,kw,kf. \\
\hline 10 & $\left(\right.$ sex* $^{*}$ adj2 victimi*).ti,ab,kw,kf. \\
\hline 11 & (unwanted pursuit or unwanted online pursuit).ti,ab,kw,kf. \\
\hline 12 & (wom\#n adj4 (safety or security)).ti,ab,kw,kf. \\
\hline 13 & or/1-12 \\
\hline 14 & Mobile Applications/ \\
\hline 15 & (app or apps).ti,ab,kw,kf. \\
\hline 16 & (application* adj4 (android or cell** or iphone* or mobile or smart phone* or smartphone*)).ti,ab,kw,kf. \\
\hline 17 & or/14-16 \\
\hline 18 & 13 and 17 \\
\hline
\end{tabular}


the databases searched (e.g., conference proceedings in Embase and Scopus) were not excluded from the search results. All searches were executed and results exported on January 23, 2020. References were deduplicated in EndNote X9 by the medical librarian according to the method developed by Bramer et al. [13].

Reference lists of systematic reviews, scoping reviews, and literature reviews that were found through the search of databases were also checked to ensure all relevant studies had been screened - including reference lists of the included studies. Last, four key journals were identified for hand-searching (Journal of Technology in Human Services, Violence Against Women, BMC Public Health, and Health Promotion International). The table of contents for the last five years (2015-2020) were searched for each journal to identify any articles that may have been missed in the database search.

\section{Selecting Relevant Studies}

All of the research articles from the database search were imported into Covidence (an online software tool for review management) for organization and screening. Inclusion and exclusion criteria were established for selecting relevant studies prior to screening began (Table 2). Our definition of sexualized violence used was broad to include any unwanted sexual contact that targets sexuality and is physical and/or psychological in nature, including sexual abuse, sexual assault, rape, sexual harassment, stalking, indecent/sexualized exposure, degrading sexual imagery, sharing sexual photographs without permission, and/or unwanted comments or jokes $[71,76]$. Sexualized violence experienced or perpetrated by a stranger or by a current or former dating/ intimate partner was included. We considered a sexualized violence-based safety app for women to be any app that protected women from danger, risk, or injury related to past, present, or future sexualized violence, including outcomes related to emotional, physical, psychological, and/or sociological health. We sought research studies that collected primary qualitative data as we were only interested in identifying women's experiences for the purposes of this scoping review, which cannot be well captured by quantitative data [29]. Literature reviews, systematic reviews, conference proceedings, and literature that did not include empirical data (commentaries, editorials, book reviews) were excluded. Mixed-methods studies were reviewed, however, only the qualitative components were considered and included if relevant. Sexualized violence interventions and resources that are meant for children or teenage girls are typically designed to meet the unique needs of minors, which differ from the needs of adults [37]. Given that our research question was interested in understanding the experiences of adult women, inclusion criteria was limited to 18 years of age or older; if an age range was not included in the study or the age range included any participants that were 17 years of age or younger, the study was excluded. Studies that had male participants were included as long as the data on women could be extracted. Studies conducted worldwide that were published in English or French were also included and all publication dates were considered for inclusion.

Four reviewers (AC, CA, ND, SW) independently screened all articles at the title/abstract stage and fulltext stage in accordance with the inclusion/exclusion criteria (each study in Covidence requires the vote of two reviewers). If voting conflicts could not be resolved by the original two reviewers, a final decision was made in collaboration with the full team. If relevance of a study could not be determined at the title/abstract stage, it was voted forward to be reviewed at the fulltext stage. Included full-text articles were obtained through online access, Dalhousie University library services, or Dalhousie University document delivery service. If full-text articles could not be obtained through these means, they were excluded. The same process was followed for hand searching.

Table 2 Inclusion and Exclusion Criteria for Selected Articles

\begin{tabular}{|c|c|}
\hline Inclusion Criteria & Exclusion Criteria \\
\hline $\begin{array}{l}\text { - Research articles including primary research. } \\
\text { - Safety apps related to sexualized violence: any unwanted sexual contact } \\
\text { that targets sexuality and is physical and/or psychological in nature per- } \\
\text { petrated by a stranger or current or former intimate/dating partner } \\
\text { - Qualitative findings (including qualitative components of mixed meth- } \\
\text { ods studies). } \\
\text { - Published in English or French. } \\
\text { - Focused on adult women's (>18 y/o) experiences of sexualized violence } \\
\text { focused safety apps. } \\
\text { - All dates and all countries. }\end{array}$ & $\begin{array}{l}\text { - Research articles that did not include primary research. } \\
\text { - Safety apps not related to sexualized violence. } \\
\text { - Quantitative findings. } \\
\text { - Not published in English or French. } \\
\text { - Data that did not focus on adult women's (<18 y/o) experiences (only men } \\
\text { or not able to extract data on women). } \\
\text { - Literature that did not include empirical data (commentaries, editorials, } \\
\text { book reviews). } \\
\text { - Literature/systematic reviews. } \\
\text { - Conference proceedings and dissertations. }\end{array}$ \\
\hline
\end{tabular}




\section{Data Charting, Extraction and Synthesis}

The following data was extracted and charted from each of the included studies by ND: author/year, title, country, purpose, participants, research method, sexualized violence focus, safety app, key findings. To ensure rigour and accuracy, a second reviewer (CA) reviewed and confirmed all extracted data. Thematic analysis guided by Braun and Clarke [17] was employed to identify emerging themes, which is a method for "identifying, analyzing, and interpreting patterns of meaning ('themes') within qualitative data" ([22], p. 297). Each reviewer (AC, CA, ND, SW) familiarized themselves with the included studies, generated initial codes, and searched for themes. Coding and preliminary themes were compared, reviewed, and defined by all reviewers. Inductive (data-driven) thematic analysis was used, which allowed the actual data (included studies) to derive analysis and the themes that emerged [17]. No software was used to organize and analyze the research data.

\section{Results}

Across the four databases searched, a total of 389 studies were identified; 127 duplicates were removed, resulting in 262 studies screened. Screening at the title and abstract level resulted in the exclusion of 182 studies. There were 80 studies screened at the full-text stage, with 74 studies being excluded - the majority (60) for wrong study design. In total, 6 studies were included from the search of databases and 1 study was included from handsearching, for a total of 7 included studies (see Fig. 1 for PRISMA diagram). Reference lists of systematic reviews, scoping reviews, and literature reviews that were found through the search of databases were also checked to ensure all relevant studies had been screened. This process did not identify any new studies.

Table 3 provides a summary of the included studies and Table 4 provides a summary of the apps featured in the included studies. Of the seven studies included, four were qualitative $[2,11,44,64]$, two were mixed-methods [10, 32], and one was a formative evaluation [52]. However, only qualitative results from all studies were charted, extracted, and synthesized. All studies used interviews or focus groups to collect qualitative data. The majority (6) of included studies were conducted in the United States $[2,10,11,32,44,52]$, with only one study conducted in Australia [64]. All included studies were published in 2013 or later. Most of the included studies' samples (4 studies) were comprised of college women $[2,10,11$, 44]. The remaining three studies recruited any women who self-reported experiencing sexualized violence [32, 52, 64]. The Gilmore et al. [32] study was the only study to report one participant who identified as neither female nor male. The Blayney et al. [10] study was the only study to report the sexual orientation of participants; the sample was comprised almost entirely of heterosexual women. Although Lindsay et al. [44] did not disclose the sexual orientation of participants, they did report that nearly $16 \%$ of their sample, which was entirely female, were in past relationships with abusive females. Five studies reported the ethno-racial makeup of their participants, and all of these studies were comprised of a majority Caucasian/White sample [2, 10, 11, 32, 44]. The included studies explored a variety of apps and focused on different aspects of sexualized violence: three studies focused on dating violence [2, 11, 44], with one study specifically focusing on same-sex dating violence [11]; one study focused on sexual victimization [10]; one study focused on sexual assault [32]; and three studies focused on intimate partner violence $[44,52,64]$.

\section{Narrative Summary of Themes}

Using thematic analysis, three themes emerged that impacted women's experiences of using sexualized violence safety apps: (1) security; (2) accessibility; and (3) knowledge. Recommendations and barriers found in relation to each theme are presented as subthemes. Table 5 offers a summary of each theme.

\section{Security}

Security was found to be a prevalent theme across studies that influenced women's experiences of using safety apps $[2,10,11,32,44,52,64]$. Specific aspects of security that were discussed included privacy, judgement, and stigma. All of the studies identified that using safety apps to obtain information provided more privacy or anonymity than obtaining information from in-person health services $[2,10,11,32,44,52,64]$. Using a safety app was also found to provide additional privacy because individuals could access them discreetly and apps were designed to be ambiguous to other; for example, using basic colours that would not be recognized as a sexualized violence related app by another person who might see the individual's phone [32, 52, 64].

Four studies noted that participants experienced a greater sense of security because they faced less judgement regarding being a victim of sexualized violence and, therefore, avoided stigma when using a safety app [11, 32, $44,64]$. Using a safety app was found to be more objective and unbiased than accessing traditional health services or speaking with friends and family [32, 44, 64], and five of the seven studies acknowledged that individuals found it was easier to interact with an app than having to discuss their situation with health professionals or their social network [2, 11, 32, 44, 64]. Women perceived less stigma about having experienced sexualized violence as a result 


$\begin{array}{cccc}\text { Embase } & \text { MEDLINE } & \text { PsycINFO } & \text { Scopus } \\ (n=81) & (n=57) & (n=52) & (n=199)\end{array}$
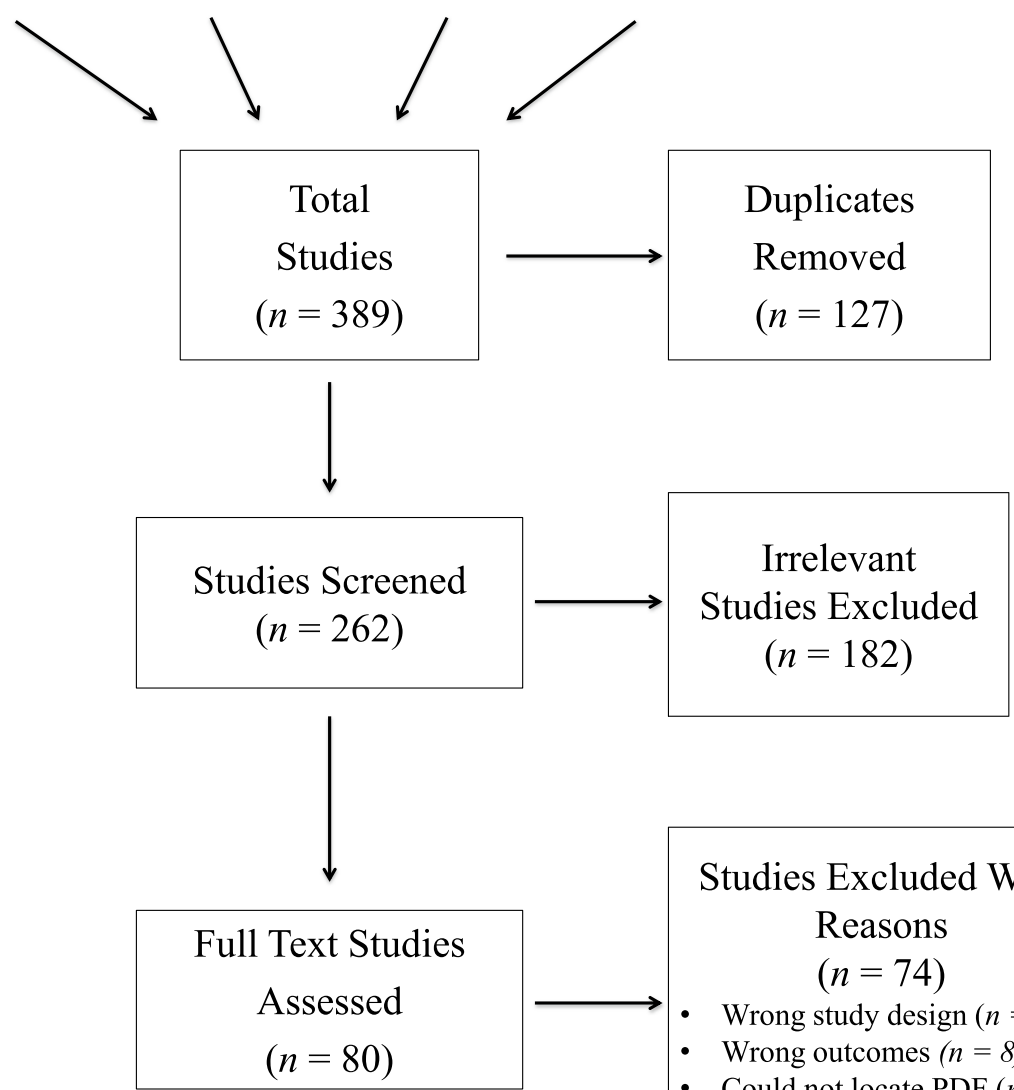

Studies Excluded With

\section{Reasons}

$(n=74)$

- Wrong study design $(n=60)$

- Wrong outcomes $(n=8)$

- Could not locate PDF $(n=2)$

- Can't separate gender data $(n$ =1)

- Duplicate $(n=1)$

- Wrong language $(n=1)$

- Wrong patient population (n =1)
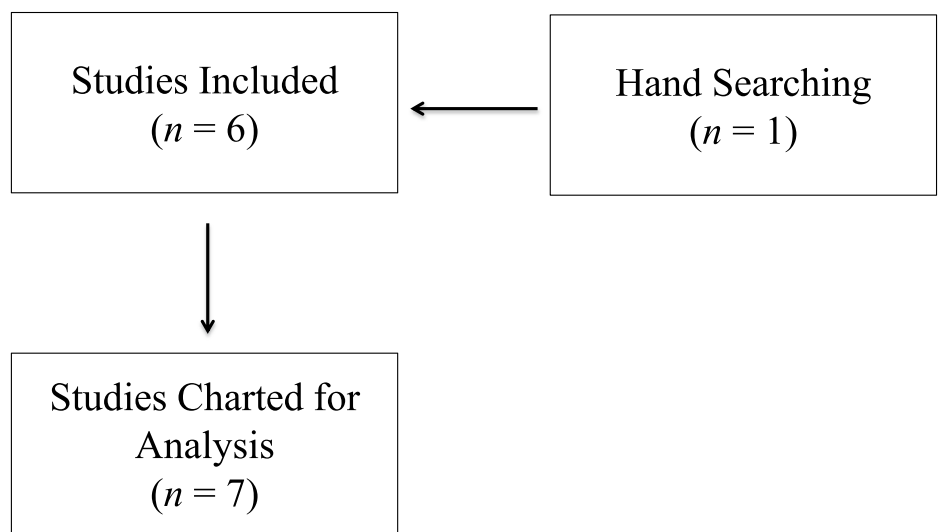

Fig. 1 PRISMA flowchart of study selection process 


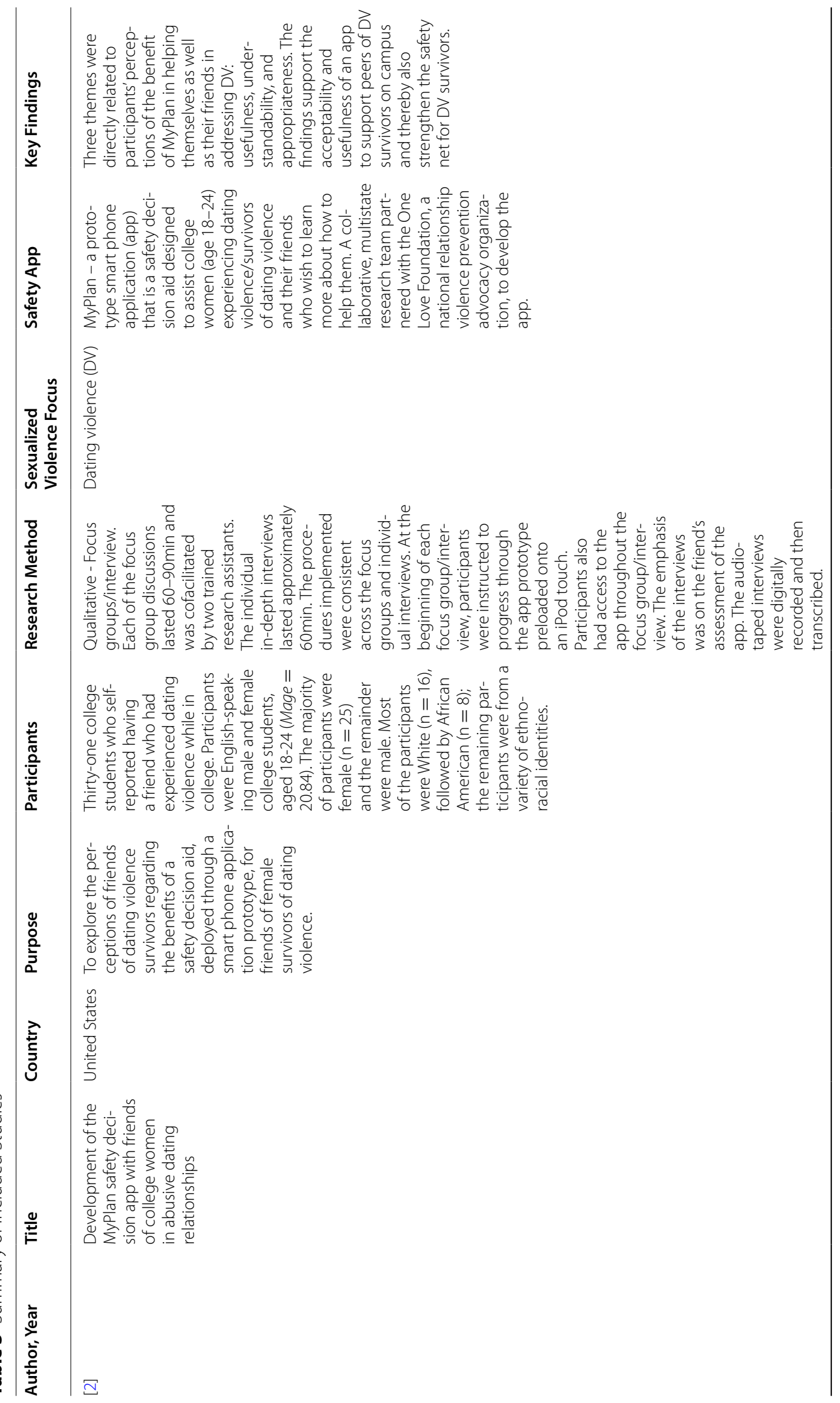




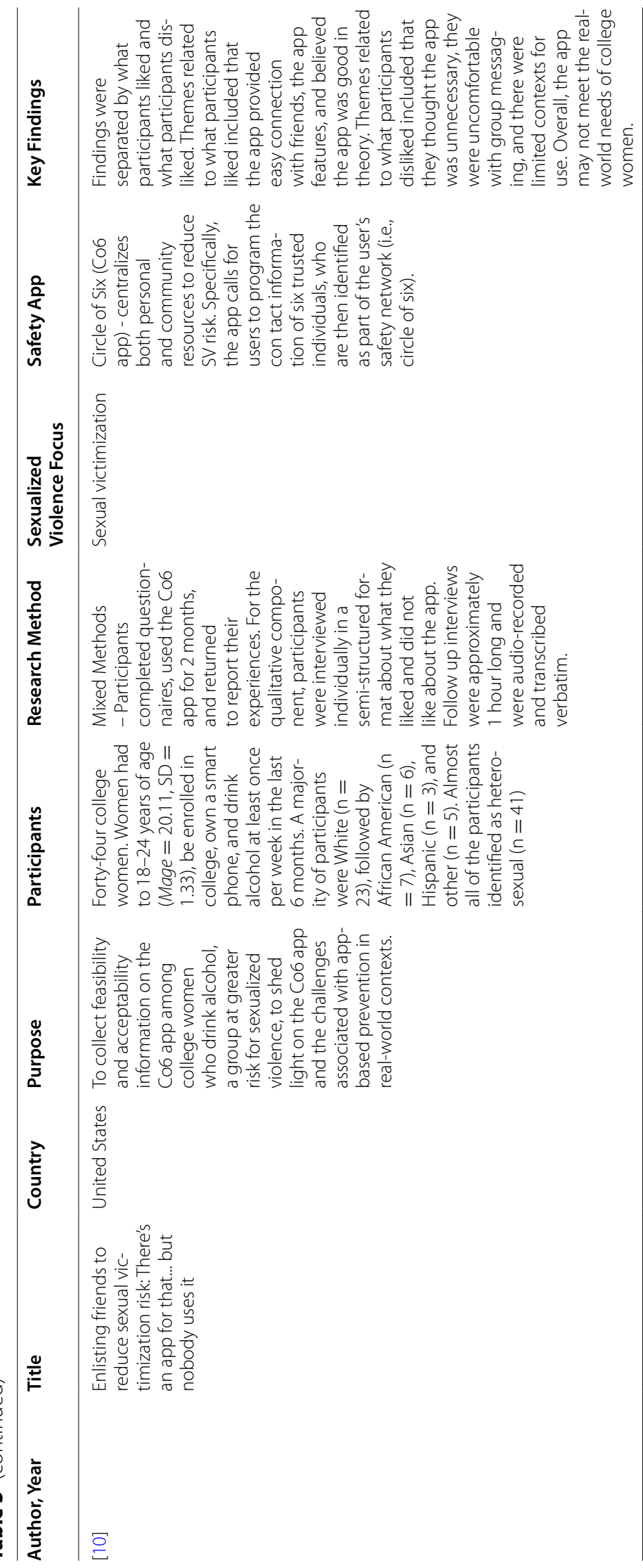




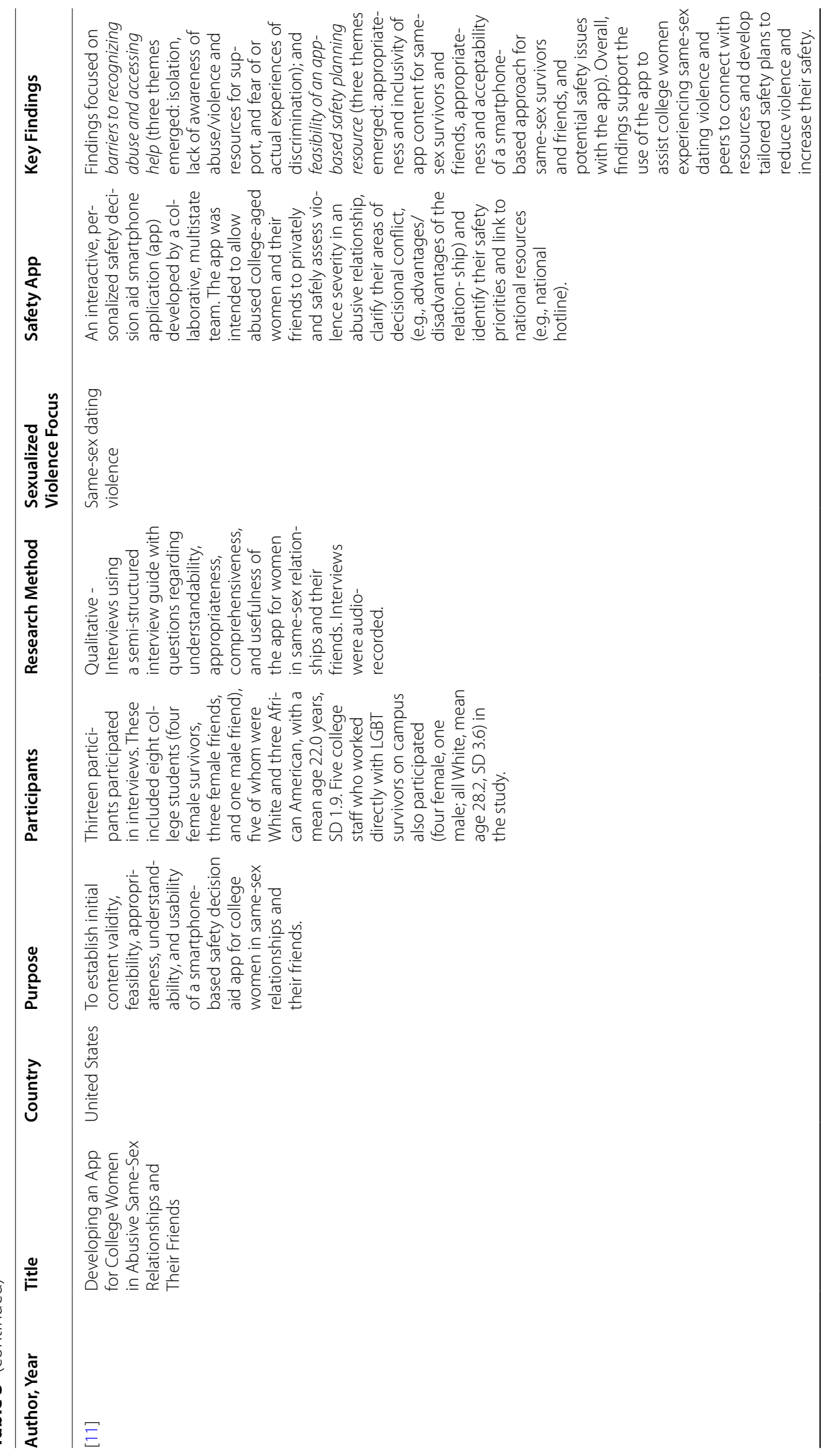




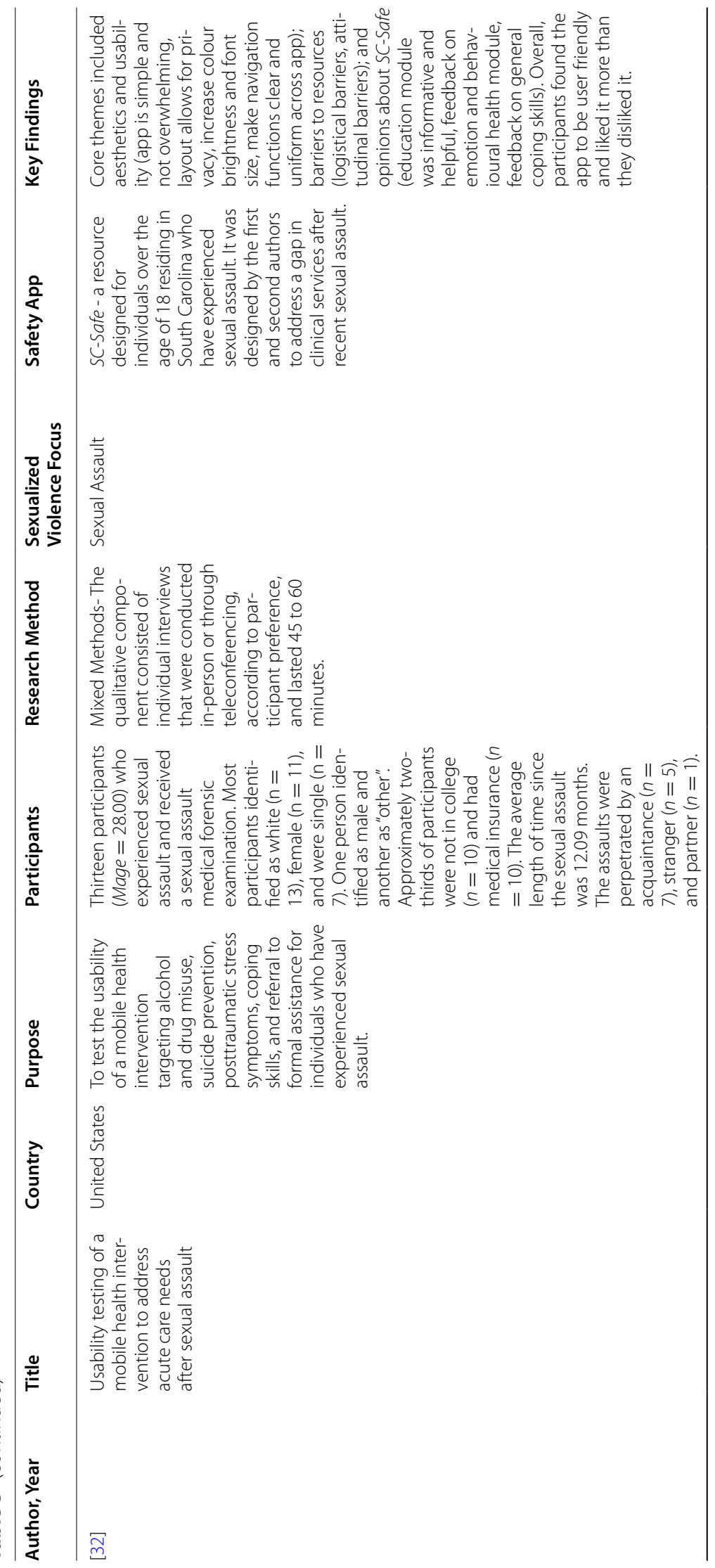




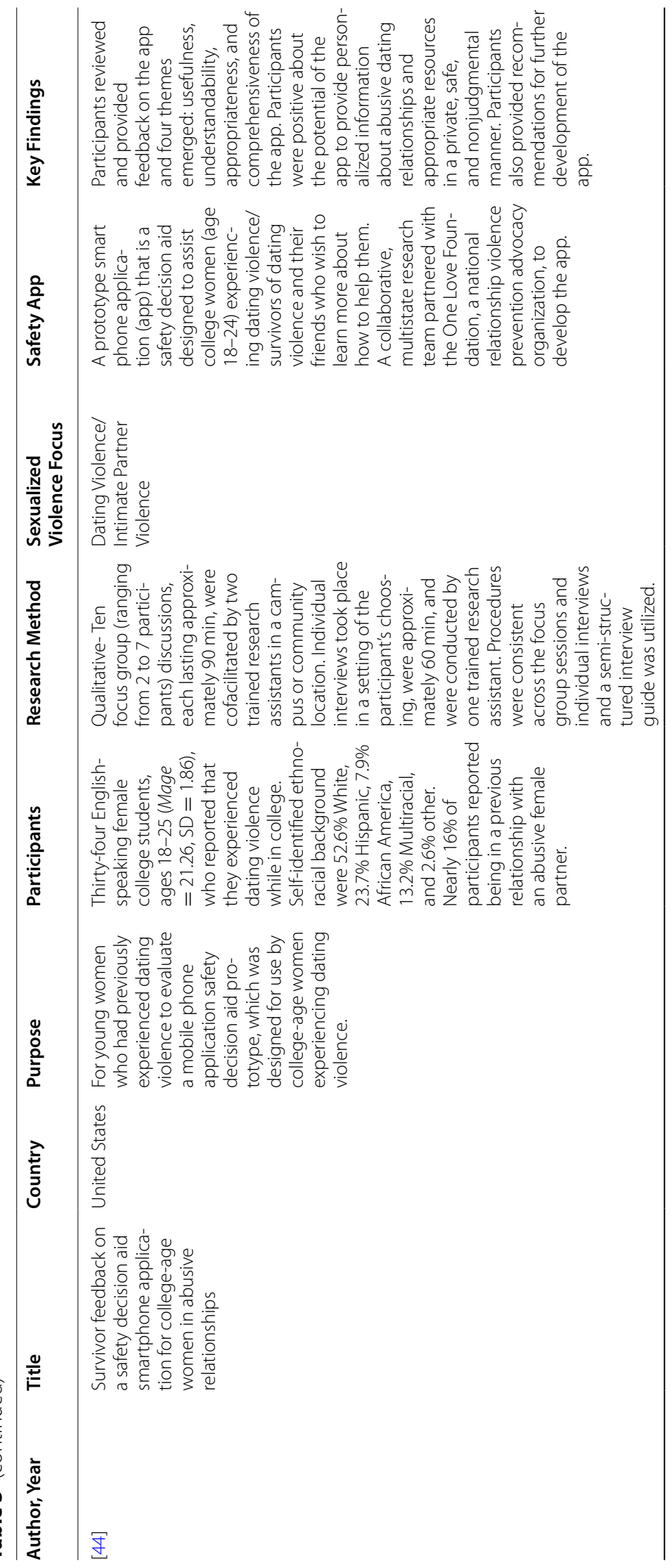




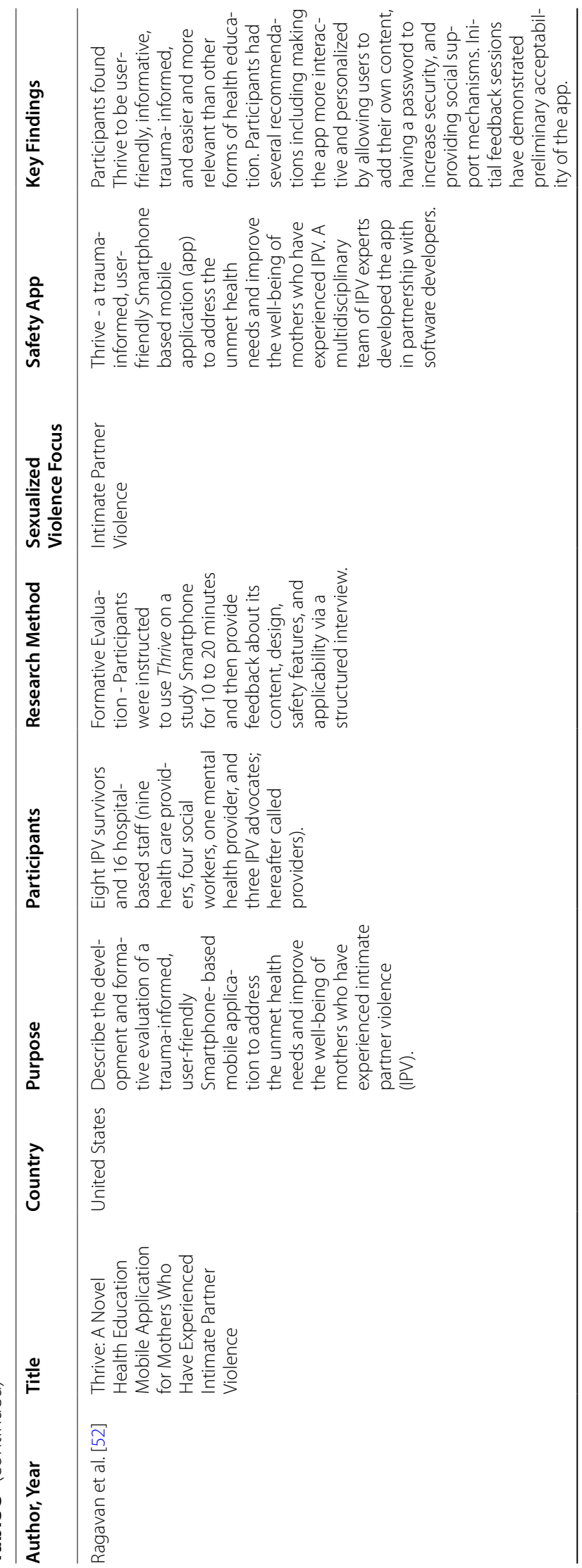




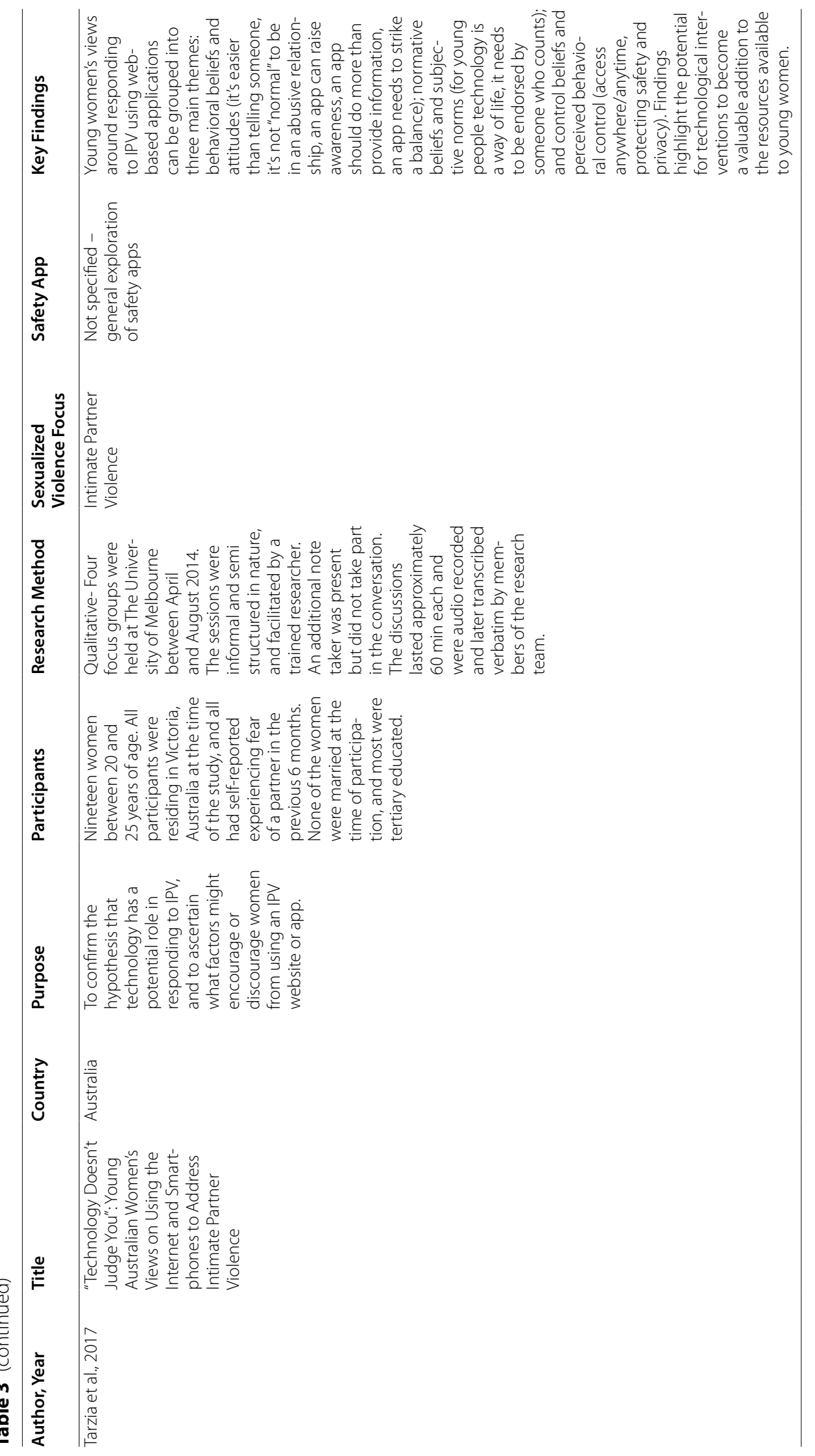




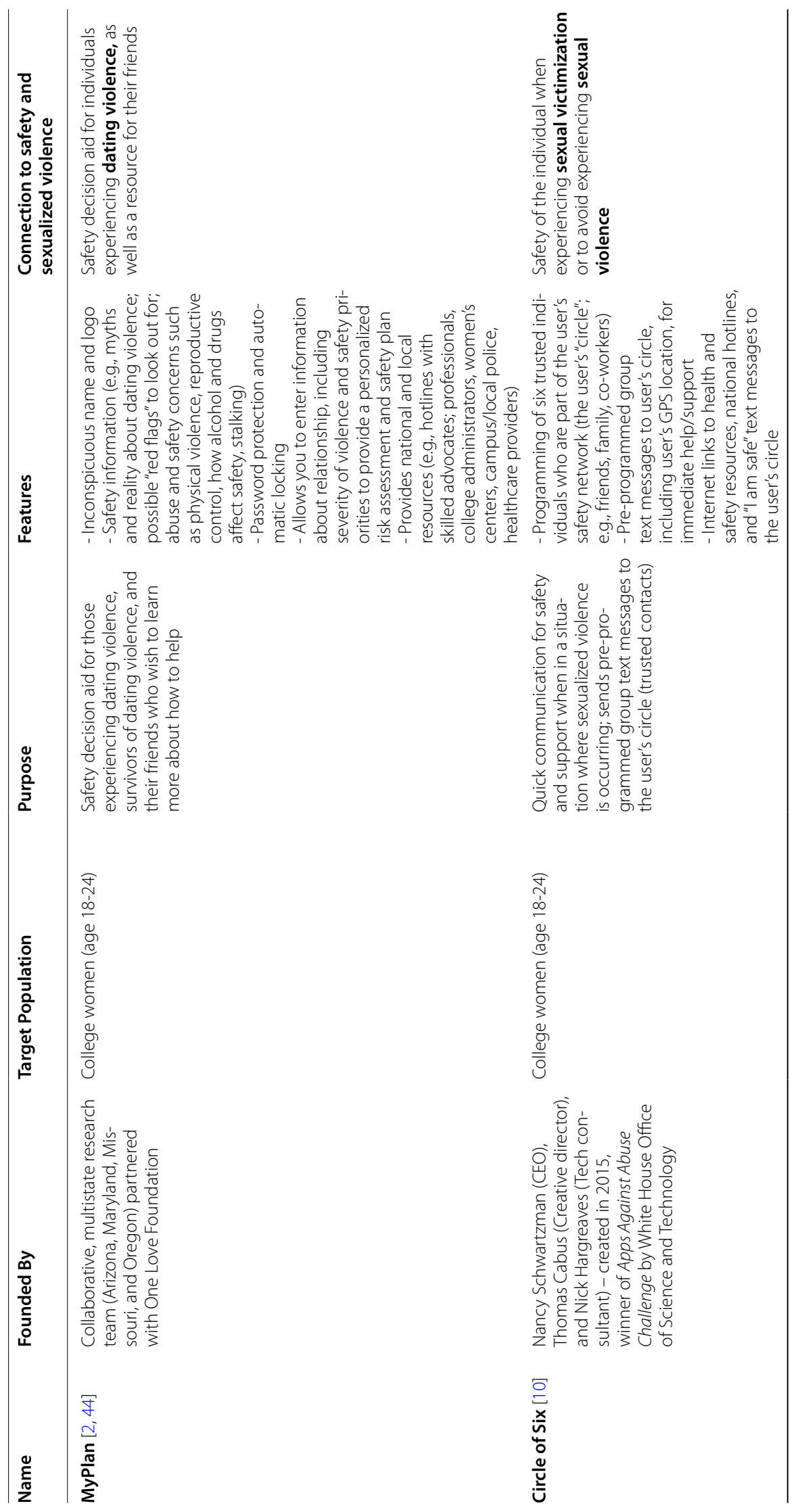




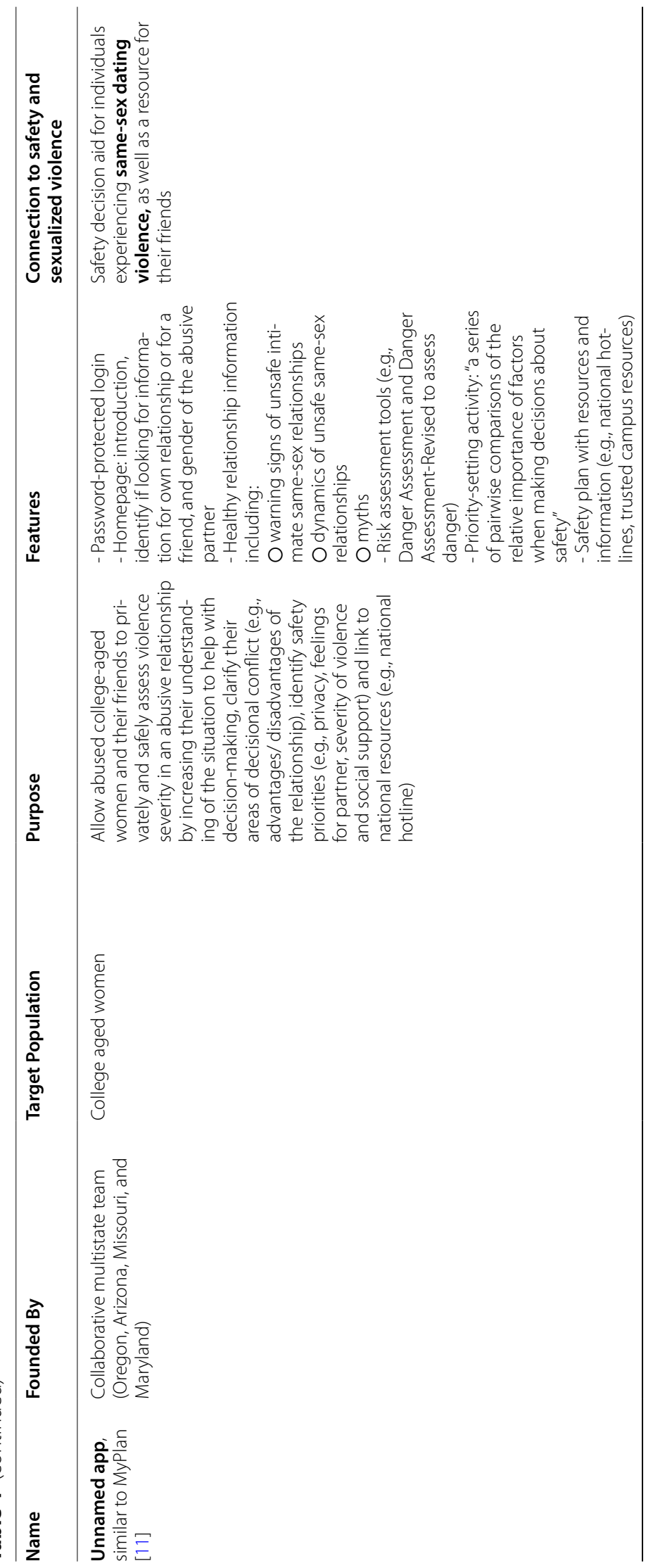




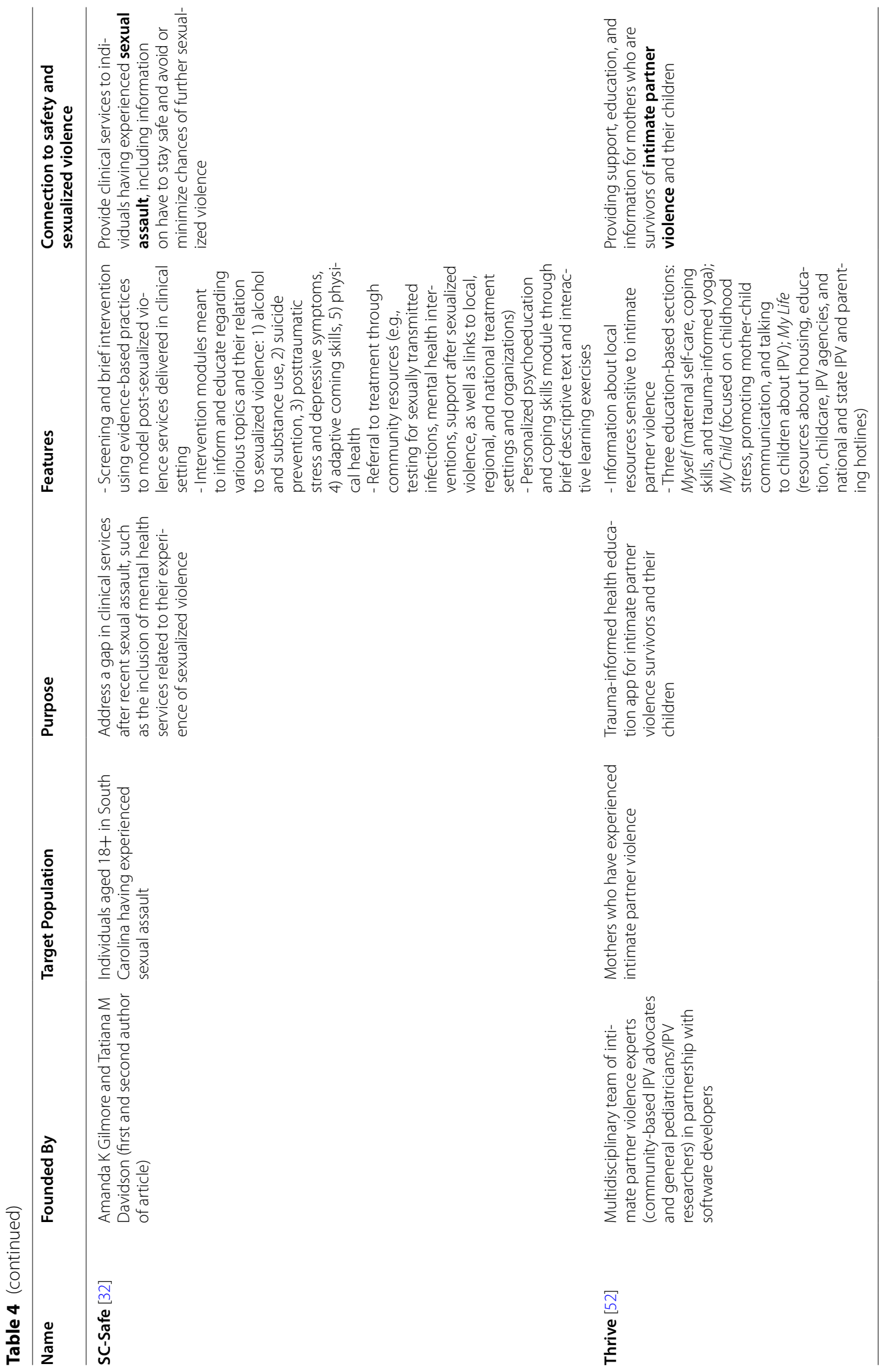




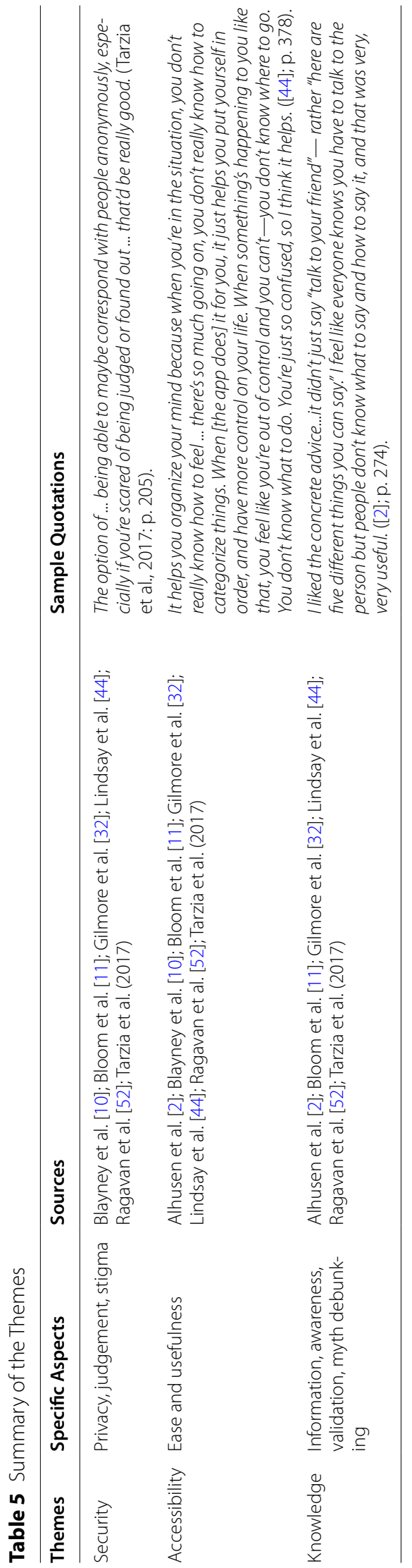


of using these apps [11, 32, 44, 64]. For example, one participant identified:

With suicide already being stigmatized the way it is, and communication about suicide being the way it is, I would want to know that like, it's okay to talk about this and it's okay if this is what you're feeling like ([32], p. 10).

Many participants mentioned the option of not having to discuss sexualized violence in a traditional way such as "face-to-face" as a benefit [2, 11, 32, 44, 64]. One participant noted, "it [app] gives you a privacy and accessibility ... the fact that I don't have to go to Student Health Center to get help and not have to worry about being judged" ([2], p. 276). Another participant discussed the benefit of accessing help via an app instead of going to a counseling center on campus, noting: "I feel judged to go ... just knowing that I'm going to see them every day since I live there [on campus] I would feel a little uncomfortable" ([2], p. 276). Interestingly, several studies identified that it would be beneficial to be able to engage with others through the app [44,52, 64], stating that "the option of ... being able to maybe correspond with people anonymously, especially if you're scared of being judged or found out ... that'd be really good" ([64], p. 205).

Barriers and recommendations The greatest barrier that emerged in relation to security was privacy, including the potential for partner monitoring or surveillance which may limit use of the app [11, 32, 44, 64]. For example, one participant commented: "If somebody's in a relationship that is abusive, and someone's already checking their phone and checking everything they're doing, and they have an app about this on their phone, it might cause issues" ([44], p. 382). Recommendations to address privacy concerns, some of which were already part of the apps studied, included providing password protection for the app [2, 44, 52, 64], an emergency exit on each screen $[11,52]$, use of an innocuous name for the app that does not refer to relationships or safety $[2,11,44,52,64]$, and even allowing the user to rename the program or change the icon themselves [11].

Bloom et al. [11] suggested the ability for users to print or e-mail the contents of the app to themselves or another person and then delete the app or the answers as a useful alternative. This would circumvent the need for the resources on the app to be exclusively on a computer or smartphone [11]. Other studies specifically recommended educating users about healthy relationship boundaries regarding technology and sharing passwords with partners and friends to better instruct users how to hide the app (e.g., bury the app in smartphone folders), and how to safely use the app if a partner monitors their phone [11, 44]. Women who reviewed the Circle of 6 (Co6) app specifically identified being uncomfortable with the group messaging feature, which is customized to send messages to only select individuals that you identify as your "circle of 6" [10].

\section{Accessibility}

The importance of accessibility emerged as a key theme that influenced experiences that women had when using sexualized violence safety apps. Accessibility included the ease and usefulness of the safety apps $[2,10,11,32,44$, $52,64]$. Women in all studies reported that they found the safety apps to be user friendly, easy to use, and easily accessible [2, 10, 11, 32, 44, 52, 64]. In six studies, the usefulness of the app was directly related to the fact that it could be used anywhere, was comprehensive in content, and all the information needed was in one place [2, 11, $32,44,52,64]$. For example, one participant commented:

\section{It helps you organize your mind because when you're in the situation, you don't really know how to feel ... there's so much going on, you don't really know how to categorize things. When [the app does] it for you, it just helps you put yourself in order, and have more control on your life. When something's happening to you like that, you feel like you're out of control and you can't-you don't know where to go. You don't know what to do. You're just so confused, so I think it helps ([44], p. 378).}

In many studies, participants found that the app could be customized or personalized to the specific user, which improved its accessibility and overall usability [2, 10, 44]. Examples of personalized or customized content included safety planning suggestions [2], messages that will be sent to friends [10], and what information is presented, such as a specific risk assessment and safety plan for the user [44]. Overall, most studies found that the accessibility of safety apps had the potential to improve safety and decrease risk $[10,11,32,44,52,64]$.

Barriers and recommendations Several studies noted suggestions to improve the accessibility of sexualized violence safety apps. Making the apps more personalized and interactive was recommended by women in five studies [10, 11, 44, 52, 64]. Examples included providing written scripts to choose from $[10,11,32]$ or the ability to connect directly with a counsellor through the app [44, 52, 64]. Other recommendations included making the navigation functions standard across the app and 
clearly indicating the purpose of each icon [32]. Celebrity endorsement was also suggested as a way to promote sexualized violence safety apps, which in turn would increase a sense of accessibility for more women [64].

Alhusen et al. [2] noted that if individuals are not ready to address the violence, then the app may be unnecessary and useless. One participant noted "If they're not ready they're not ready... don't talk about them behind their back and don't talk about them with others [on an app] ([2], p. 276)". Further, women in the Blayney et al. [10] study noted the app had limited contexts for use and did not provide anything more than a mobile phone could offer, seeing the app as unnecessary. Feedback included:

\section{It just generally seemed like you could do the same things without the app, because iPhones nowadays are so intricate. Like, you could click details on your messages and press 'send location' and type a short message. I feel like that wouldn't take nearly as long as opening the app, clicking the button, sending the messages... It's not really an easy way to contact friends, I think personally for me, it would just be easier to call or text them. Like it wasn't any easier to do that [use the app] ([10], p. 771).}

\section{Knowledge}

Six studies discussed the importance of knowledge in the experiences of women when using sexualized violence safety apps [2, 11, 32, 44, 52, 64]. How women experienced the knowledge provided on the safety apps was dependent on the information provided, and if the information increased awareness, validation, and myth debunking. In all six studies, participants found the safety apps to be helpful in raising awareness of sexualized violence and recognizing violent behaviour through various ways such as myth debunking $[2,11$, $32,44,52,64]$. Additionally, six studies found the apps to be an easy way to acquire information that validated women's experiences of violence and indicated that participants found the app provided assurance that they are not alone $[10,11,32,44,52,64]$.

Further, six studies found that women believed the apps to contain relevant information that was credible, evidence based, and/or trauma informed [2, 11, 32, $44,52,64]$. In relation to providing knowledgeable and credible information, one participant commented:

I liked the concrete advice...it didn't just say "talk to your friend"- rather "here are five different things you can say." I feel like everyone knows you have to talk to the person, but people don't know what to say and how to say it ([2], p. 274).

Similarly, another participant commented that the app "arms you with ideas as to how to go about it [conversations] properly" ([2]; p. 276).

The information, options, choices, and safety planning strategies provided on the safety apps were also found to increase a feeling of empowerment $[2,11$, 44, 64]. For example, one participant commented: "[A young woman] should feel relieved. Like she is equipped to know what to do, and not lost and drowning her sorrows and burden by herself. Like someone is there to help her" ([64] p. 209).

Barriers and recommendations Several studies noted recommendations for improving the knowledge provided on sexualized violence safety apps. Several women thought that personal anecdotes, rather than statistics about dating violence, might better help young women recognize the violence in their own relationships $[11,52]$. Gilmore et al. [32] and Lindsay et al. [44] found that some young women noted the desire for more information throughout the app about emotional abuse, as illustrated by the following participant: "It would be really cool if there was more stuff about emotional abuse and control because I think that is also really important" ([44], p. 383). Survivors thought information about what the police can and cannot do to assist the survivor would also be helpful because "talking to police can be kinda scary" ([44], p. 383). Last, several studies believed that sexualized violence safety apps should do more than just provide information [11, 32, 44, 64]. In addition to providing information, the safety apps need to expand the ability to gain knowledge by including information for appropriate resources [11, 32, 64] and incorporating further educational modules and learning opportunities [11,32].

\section{Discussion}

This scoping review was conducted to explore the nature and extent of literature on women's experiences of safety apps related to sexualized violence. To our knowledge, this is the first scoping review to explore this topic. While most safety apps are studied through quantitative measures to determine prevalence of use and downloads, as well as content creation (e.g., $[30,46])$, quantitative data is limited in its ability to capture the lived experiences of participants [29]. The current scoping review therefore was designed to focus solely on qualitative studies. Within the literature reviewed, three common themes emerged that influenced women's experiences of sexualized violence safety apps: security, accessibility, and knowledge. This review, however, confirms that the 
qualitative literature on women's experiences of sexualized violence safety apps is scarce and exposes a gap in the literature on this topic does indeed exist.

Of the seven studies included, the majority of the samples comprised of Caucasian/White females, and there was an under-representation of other ethno-racial groups $[2,10,11,32,44]$. Moreover, only one study disclosed the sexual orientation of their participants, which comprised of predominantly heterosexual females [10]. There was one other study that included a participant that identified as neither female nor male [32], which is insufficient to capture the experiences of gender-non-conforming and trans persons. Given the widespread evidence that members from diverse ethno-racial identities and the sexual and gender diverse community are often victims of unique forms of sexualized violence [23, 38, 43], our review has highlighted a significant gap in this literature. Future research should aim to recruit samples that are entirely, or predominantly, comprised of members of diverse communities to better understand their unique experiences and needs regarding sexualized violence safety-apps. There is a need for research that explores the unique experiences of women with diverse gender and ethno-racial identities.

From the included studies in this review, it became evident that feelings of security and privacy were of utmost importance to the women using the apps [10, $11,32,44,52,64]$. Some women felt an increased sense of privacy while using the app, which allowed them to feel more comfortable and secure, as well as less judged and stigmatized by others. While certain apps were praised for their discrete icons and layouts [11, 32], one article specifically discussed the for improvements in this area through increased password protection and a "quick exit" button or feature to disguise the app's purpose to an onlooker [52]. The concept of privacy on apps has become a key concern for many app users, often in regards to sharing of sensitive user data $[6,28]$, or where data will be stored [35]. For health apps specifically, a fear surrounding privacy lies in the potential of unauthorised use or disclosure of health information, which could lead to social stigma and discrimination [39]. A quantitative study with a focus on how privacy is valued by app users across a variety of apps (e.g., care sharing, diabetes app, companion and security app, and mood adjustment app) found that premium (i.e. at a cost) privacy features were more favourable than others, such as premium functions and personalization [27]. As demonstrated through the literature, most privacy concerns were related to sharing personal information, whereas the studies in this review discussed privacy in the context of shielding their use of the app from a partner or from social networks.
Our review found that accessibility, inclusive of how easy and useful the app was perceived to be, was integral to the user experience. App content and design has been directly related to accessibility and the rate of use in other literature. The connection between ease of use and a user's experience has been widely discussed, especially among health apps (e.g., [4, 26, 55, 72]). For example, a qualitative study exploring user experiences of mobile health apps found that an apps ease of use led to more desire to use the app [4]. Features that made the app easy to use were automation of in-app functions that reduced time in performing tasks, and convenience such as having information for a person's self-management plan in one location [4]. In a qualitative study on barriers and facilitators of medical mobile app use, app features such as information content, accessibility of the information, and ease of use of the app, were highlighted as facilitators that promoted use of the app [72]. Another study, which explored factors that influence use of a mobile app for reporting adverse drug reactions and receiving safety information, found that use of the app was influenced by ease of use and the security of the app [26]. Overall, it is apparent that an apps ease of use is an integral part of the user experience.

The reviewed literature found that increased information, awareness, validation, and myth debunking were positive knowledge features on sexualized violence safety apps [2, 11, 32, 44, 52, 64]. It was also found that users appreciated information that was trauma informed, credible and evidence based [2, 11, 32, 44, 52, 64]. Similar to our findings, a study examining help-seeking for domestic violence victims found that apps were a particularly good avenue for accessing information [25]. Other literature has reported that mobile apps with high quality education materials can significantly increase the knowledge of users [40] and directly influence their attitudes and behaviours $[42,58]$. It is important to note that sexualized violence safety apps can also be used to inform individuals who are not victims or perpetrators, such as bystanders. Shaw and Janulis [57] found that bystander education increased sexualized violence knowledge, decreased the likelihood of endorsing rape myths, and increased a sense of efficacy for intervening as a bystander. Last, apps provide a convenient and affordable way to access information that is often interactive and are an environmentally friendly alternative to information that is often conveyed on paper [42].

The use of technology to increase safety is not a novel concept. For example, ride-share apps such as Uber offer GPS tracking that can be shared with family and friends in real time, as well as a distress alarm available on the app that can signal the ride-sharing service for help [21]. Increased safety through technology can also be in the 
form of delivering safety information, such as the use of mobile technology for delivery safety awareness in the workplace [54] and communicating emergency safety information through mobile text alerts [73]. Safety in relation to technology and sexualized violence, however, has primarily been discussed negatively. The use of social media, personal tracking applications, and smartphone technology in general have been found to facilitate forms of sexualized violence, such as harassment, stalking, violence, and dating abuse [38]. Interestingly, despite these challenges, a study by Finn and Atkinson [30] found that women who experience sexualized violence through technology still feel a sense of independence when using technology. This aligns with the findings presented in this review, which found that the women who had experienced sexualized violence felt that safety apps provided them with increased knowledge, anonymity, validation, and a sense of empowerment [11, 44, 64].

\section{Limitations}

Quality appraisal is not a compulsory component of the Arksey and O'Malley [5] scoping review framework, and the included studies in this scoping review were not critically appraised. Although this scoping review did not seek to assess quality of evidence, it consequently cannot determine whether the included studies provide robust or generalizable findings or if the research itself is of poor quality. Literature that was not included in this review included reviews, commentaries, editorials, and conference proceedings. Existing networks and relevant organizations were also not contacted. While the search was broad, some relevant studies may have been omitted. In addition, the review only included literature published in English and French and, therefore, relevant literature may have been omitted if published in other languages. Although many apps are currently being created and developed, they may not be at the user testing phase or are not explicitly looking at users' experiences beyond interface evaluations. Despite these limitations, the review does provide important understandings of women's experiences of sexualized violence safety-apps.

\section{Conclusion}

This scoping review provides a comprehensive summary of the qualitative research findings in relation to women's experiences of sexualized violence safety apps. This review has highlighted that there is limited research conducted in this area. Victims of sexualized violence are in a unique position to provide insight to app developers on their priorities and specific needs, which can potentially change the way women utilize app technology for their safety. Additional research that focuses on the experiences of women users will help to better inform quality app development that is secure, informative, useful, and wanted by the user. Overall, the reviewed literature in this study found safety apps to be a private all-in-one resource for support, information, and emergency planning that were useful and easy to use. Further, women believed that sexualized violence safety apps had the potential to decrease the overall risk of experiencing sexualized violence.

\section{Supplementary Information}

The online version contains supplementary material available at https://doi. org/10.1186/s12889-021-12292-5.

Additional file 1.

\section{Acknowledgements}

The Maritime SPOR SUPPORT Unit.

\section{Authors' contributions}

ND- conception, design, analysis, interpretation, manuscript writing. CA- conception, design, analysis, interpretation, manuscript writing. SW- conception, design, analysis, interpretation, manuscript writing. AC-conception, design, analysis, interpretation, manuscript writing. JS- Review of manuscript. LBdesign, manuscript writing, review of manuscript. MN- Review of manuscript. The authors read and approved the final manuscript.

\section{Funding}

N/A

\section{Declarations}

Availability of data and materials

N/A

Ethics approval and consent to participate

N/A

Consent for publication

N/A

Competing interests

N/A

\section{Author details}

${ }^{1}$ Dalhousie University, 6299 South St, Halifax, NS B3H 4R2, USA. ${ }^{2}$ University of Toronto, 155 College St Room 500, Toronto, ON M5T 3M7, USA. ${ }^{3}$ Maritime SPOR SUPPORT Unit, 5790 University Avenue, Halifax, NS B3H 1V7, USA.

Received: 19 May 2020 Accepted: 22 November 2021

Published online: 30 December 2021

References

1. Abroms LC, Padmanabhan N, Thaweethai L, Phillips T. iPhone apps for smoking cessation: A content analysis. Am J Prev Med. 2011;40:279-85. https://doi.org/10.1016/j.amepre.2010.10.032.

2. Alhusen J, Bloom T, Clough A, Glass N. Development of the MyPlan Safety Decision App with Friends of College Women in Abusive Dating Relationships. J Technol Hum Serv. 2015;33(3):263-82.

3. Amstadter AB, McCauley JL, Ruggiero KJ, Resnick HS, Kilpatrick DG. Selfrated health in relation to rape and mental health disorders in a national sample of women. Am J Orthopsychiatry. 2011;81(2):202-10. 
4. Anderson K, Burford O, Emmerton L. Mobile health apps to facilitate self-care: A qualitative study of user experiences. PLoS One. 2016;11(5):e01561646. https://doi.org/10.1371/journal.pone.0156164.

5. Arksey H, O'Malley L. Scoping studies: Towards a methodological framework. Int J Soc Res Methodol. 2005:8(1):19-32.

6. Avancha S, Baxi A, Kotz D. Privacy in mobile technology for personal healthcare. ACM Computing Surveys (CSUR). 2012;45(1):3. https://doi. org/10.1145/2379776.2379779.

7. Beck JG, Grant DM, Clapp JD, Palyo SA. Understanding the interpersonal impact of trauma: Contributions of PTSD and depression. J Anxiety Disord. 2009;23:443-50. https://doi.org/10.1016/j.janxdis.2008.09.001.

8. Bedard-Gilligan M, Kaysen D, Desai S, Lee CM. Alcohol-involved assault:Associations with posttrauma alcohol use, consequences, and expectancies. Addict Behav. 2011;36:1076-82. https://doi.org/10.1016/j. addbeh.2011.07.001.

9. Benoit C, Shumka L, Phillips R, Kennedy MC, Belle-Isle L. Issue Brief: Sexual Violence Against Women in Canada. 2015. Retrieved from https://www. swc-cfc.gc.ca/svawc-vcsfc/index-en.htm

10. Blayney J, Jenzer T, Read J, Livingston J, Testa M. Enlisting friends to reduce sexual victimization risk: There's an app for that... but nobody uses it. J Am Coll Heal. 2018:66(8):767-73.

11. Bloom T, Gielen A, Glass N. Developing an App for College Women in Abusive Same-Sex Relationships and Their Friends. J Homosex. 2016;63(6):855-74.

12. Bivens R, Hasinoff AA. Rape: is there an app for that? An empirical analysis of the features of anti-rape apps. Inf Commun Soc. 2018;21 (8):1050-67.

13. Bramer WM, Giustini D, de Jonge GB, Holland L, Bekhuis T. De-duplication of database search results for systematic reviews in EndNote. JMLA. 2016;104(3):240.

14. Breiding MJ, Chen J, Black MC. Intimate partner violence in the United States--2010. 2014.

15. Breland JY, Yeh VM, Yu J. Adherence to evidence-based guidelines among diabetes self-management apps. Transl Behav Med. 2013;3:277-86. https://doi.org/10.1007/s13142-013-0205-4.

16. Breton ER, Fuemmeler BF, Abroms LC. Weight loss-There is an app for that! But does it adhere to evidence-informed practices? Transl Behav Med. 2011;1:523-9. https://doi.org/10.1007/s13142-011-0076-5.

17. Braun V, Clarke V. Using thematic analysis in psychology. Qual Res Psychol. 2006;3(2):77-101.

18. Brignone L, Edleson JL. The dating and domestic violence app rubric: Synthesizing clinical best practices and digital health app standards for relationship violence prevention smartphone apps. In J Hum-Comput Interact. 2019;35(19):1859-69.

19. Campbell R, Dworkin E, Cabral G. An ecological model of the impact of sexual assault on women's mental health. Trauma Violence Abuse. 2009;10(3):225-46.

20. Cardoso LF, Sorenson SB, Webb O, Landers S. Recent and emerging technologies: Implications for women's safety. Technol Soc. 2019;58:101108.

21. Chaudhry B, Yasar A-U-H, El-Amine S, Shakshuki E. Passenger safety in ride-sharing services. Procedia Comput Sci. 2018;130:1044-50.

22. Clarke V, Braun V. Thematic analysis. J Posit Psychol. 2017;12(3):297-8.

23. Conroy S, Cotter A. Self-reported sexual assault in Canada, 2014. 2017 Retrieved from https://www150.statcan.gc.ca/n1/en/pub/85-002-x/ 2017001/article/14842-eng.pdf?st=M2AKlaM3

24. Cotter A, Savage L. Gender-based violence and unwanted sexual behaviour in Canada, 2018: Initial findings from the Survey of Safety in Public and Private Spaces. 2019. https://www150.statcan.gc.ca/n1/ pub/85-002-x/2019001/article/00017-eng.htm

25. Cotton S, Gupta S. Characteristics of online and offline health information seekers and factors that discriminate between them. Soc Sci Med. 2004:59:1795-806.

26. de Vries ST, Wong L, Sutcliffe A, Houÿez F, Ruiz CL, Mol PGM. Factors influencing the use of a mobile app for reporting adverse drug reactions and receiving safety information: A qualitative study. Drug Saf. 2017:40:443-55.

27. Dogruel L, Joeckel S, Vitak J. The valuation of privacy premium features for smartphone apps: The influence of defaults and expert recommendations. Comput Hum Behav. 2017;77:230-9.

28. Egelman S, Felt AP, Wagner D. Choice architecture and smartphone privacy: There's a price for that. In: Bohme R, editor. The economics of information security and privacy. Berlin, Heidelberg: Springer; 2013. p. $211 \mathrm{e} 236$

29. Finn J. A survey of online harassment at a university campus. J Interpers Violence. 2004;19(4):468-83.

30. Finn J, Atkinson T. Promoting the safe and strategic use of technology for victims of intimate partner violence: Evaluation of the Technology Safety Project. J Fam Violence. 2009;24(1):53-9.

31. Forbes D, Phelps A, McFarlane A. Trauma at the hands of another: Longitudinal study of differences in the posttraumatic stress disorder symptom profile following interpersonal compared with noninterpersonal trauma. J Clin Psychiatry. 2012;73:372-6. https://doi.org/10.4088/ JCP.10m06640

32. Gilmore A, Davidson T, Leone R, Wray L, Oesterle D, Hahn C, ... Acierno R. Usability Testing of a Mobile Health Intervention to Address Acute Care Needs after Sexual Assault. Int J Environ Res Public Health. 2019;16(17):3088.

33. Glass N, Clough A, Case J, Hanson G, Barnes-Hoyt J, Waterbury A, Perrin N. A safety app to respond to dating violence for college women and their friends: the MyPlan study randomized controlled trial protocol. BMC Public Health. 2015;15(1):1-13.

34. Glass N, Eden KB, Bloom T, Perrin N. Computerized aid improves safety decision process for survivors of intimate partner violence. J Interpers Violence. 2010;25(11):1947-64. https://doi.org/10.1177/0886260509354508.

35. He D, Naveed M, Gunter CA, Nahrstedt K. Security concerns in Android mHealth apps. In: AMIA Annual Symposium Proceedings (Vol. 2014). American Medical Informatics Association; 2014. p. 645.

36. Halstead V, Williams JR, Gonzalez-Guarda R. Sexual violence in the college population: A systematic review of disclosure and campus resources and services. J Clin Nurs. 2017;26(15-16):2137-53.

37. Hébert M, Moreau C, Blais M, Lavoie F, Guerrier M. Child sexual abuse as a risk factor for teen dating violence: Findings from a representative sample of Quebec youth. J Child Adolesc Trauma. 2017;10(1):51-61.

38. Henry N, Powell A. Technology-facilitated sexual violence: A literature review of empirical research. Trauma Violence Abuse. 2018;19(2):195-208.

39. Hodge JG Jr, Gostin LO, Jacobson PD. Legal issues concerning electronic health information: privacy, quality, and liability. JAMA. 1999:282:1466-71.

40. Ismail SNS, Rangga JU, Rasdi I, Rahman URA, Samah MAA. Mobile apps application to improve safety and health knowledge, attitude and practice among university students. Malaysian J Med Health Sci. 2018;14(SP1):47-55.

41. Koss MP, Figueredo AJ, Prince RJ. Cognitive mediation of rape's mental, physical and social health impacts: Tests of four models in cross-sectional data. J Consult Clin Psychol. 2002;70(4):926.

42. Kumar S. E- and M-Learning: A comparative study. Int J New Trends Educ Their Implications. 2013;4(3):65-78.

43. Langenderfer-Magruder L, Walls NE, Kattari SK, Whitfield DL, Ramos D. Sexual victimization and subsequent police reporting by gender identity among lesbian, gay, bisexual, transgender, and queer adults. Violence Vict. 2016;31(2):320-31.

44. Lindsay M, Messing J, Thaller J, Baldwin A, Clough A, Bloom T, ... Glass N. Survivor Feedback on a Safety Decision Aid Smartphone Application for College-Age Women in Abusive Relationships. J Technol Hum Serv. 2013;31(4):368-88.

45. Maxwell L, Sanders A, Skues J, Wise L. A content analysis of personal safety apps: Are they keeping us safe or making us more vulnerable? Violence Against Women. 2020;26(2):233-48.

46. McCarthy OT, Caulfield B, O'Mahony M. How transport users perceive personal safety apps. Transp Res F. 2016;43:166-82.

47. Millon EM, Chang HYM, Shors TJ. Stressful life memories relate to ruminative thoughts in women with sexual violence history, irrespective of PTSD. Front Psychiat. 2018;9:311

48. Mortimer S, Powell A, Sandy L.'Typical scripts' and their silences: Exploring myths about sexual violence and LGBTQ people from the perspective of support workers. Curr Issues Crim Just. 2019;31(3):333-48. https://doi. org/10.1080/10345329.2019.1639287.

49. Office for National Statistics. Sexual offences in England and Wales: Year ending March 2017. 2017. Retrieved from https://www.ons.gov.uk/peopl epopulationandcommunity/crimeandjustice/articles/sexualoffencesi nenglandandwales/ingmarch2017.

50. Pegram SE, Abbey A. Associations between sexual assault severity and psychological and physical health outcomes: Similarities and differences 
among African American and Caucasian survivors. J Interp Viol. 2019;34(19):4020-40.

51. Peters MD, Marnie C, Tricco AC, Pollock D, Munn Z, Alexander L, Khalil H. Updated methodological guidance for the conduct of scoping reviews. JBI Evid Synth. 2020;18(10):2119-26.

52. Ragavan M, Ferre V, Bair-Merritt M. Thrive: A Novel Health Education Mobile Application for Mothers Who Have Experienced Intimate Partner Violence. Health Promot Pract. 2020;21(2):160-4.

53. Resick PA. The psychological impact of rape. J Interpersonal Viol. 1993;8(2):223-55.

54. Rodriguez A, Hagevoort GR, Leal D, Pompeii L, Douphrate DI. Using mobile technology to increase safety awareness among dairy workers in the United States. J Agromed. 2018;23(4):315-26. https://doi.org/10.1080/ 1059924X.2018.1502704.

55. Scheper H, Derogee R, Mahdad R, van der Wal RJP, Nelissen RGHH, Visser LG, de Boer MGJ. A mobile app for postoperative wound care after arthroplasty: Easy of use and perceived usefulness. Int J Med Inform. 2019;129:75-80. https://doi.org/10.1016/j.jimedinf.2019.05.010.

56. Scott KM, Koenen KC, King A, Petukhova MV, Alonso J, Bromet EJ, et al. Post-traumatic stress disorder associated with sexual assault among women in the WHO World Mental Health Surveys. Psychol Med. 2018:48(1):155-67.

57. Shaw J, Janulis P. Re-evaluating sexual violence prevention through bystander education: A latent growth curve approach. J Interpersonal Viol. 2016;31(16):2729-50.

58. Shin D, Shin Y, Choo H, Beom K. Smartphones as smart pedagogical tools: Implications for smartphones as u-learning devices. Comput Hum Behav. 2011;27(6):2207-14

59. Silver L. Smartphone Ownership Is Growing Rapidly Around the World, but Not Always Equally. 2019. Retrieved from https://www.pewresearch. org/global/2019/02/05/smartphone-ownership-is-growing-rapidlyaround-the-world-but-not-always-equally/

60. Smith A, Rainie L, Zickuhr K. College students and technology. Pew Internet Research Project. 2011. Retrieved from http://www.pewinternet.org/ 2011/07/19/college-students-and-technology/

61. Spohn R, Wright EM, Peterson JC. Rape and mental health outcomes among women: Examining the moderating effects of "healthy"fear levels. Violence Against Women. 2017:23(9):1055-75.

62. Statistica. Rape and sexual assault victims in the U.S. 2000-2018, by gender. 2019. Retrieved from https://www.statista.com/statistics/642458/ rape-and-sexual-assault-victims-in-the-us-by-gender/

63. Stoner JE, Cramer RJ. Sexual violence victimization among college females: A systematic review of rates, barriers, and facilitators of health service utilization on campus. Trauma Violence Abuse. 2019;20(4):520-33.

64. Tarzia L, Iyer D, Thrower E, Hegarty K. "Technology Doesn't Judge You": Young Australian Women's Views on Using the Internet and Smartphones to Address Intimate Partner Violence. J Technol Hum Serv. 2017;35(3):199-218.

65. Tarzia L, Maxwell S, Valpied J, Novy K, Quake R, Hegarty K. Sexual violence associated with poor mental health in women attending Australian general practices. Aust N Z J Public Health. 2017:41(50):518-23.

66. Truman JL, Langton L. Criminal victimization, 2013. U.S. Department of Justice. 2014. Retrieved from http://www.bjs.gov/content/pub/pdf/cv13. pdf

67. Truman JL, Morgan RE. Criminal victimization, 2015. U.S. Department of Justice. 2016. Retrieved from https://www.bjs.gov/content/pub/pdf/ cv15.pdf

68. Ullman SE, Brecklin LR. Sexual assault history and suicidal behavior in a national sample of women. Suicide Life Threat Behav. 2002;32:117-30. https://doi.org/10.1521/suli.32.2.117.24398.

69. UN Women. Facts and figures: Ending violence against women. 2021. Retrieved from https://www.unwomen.org/en/what-we-do/ending-viole nce-against-women/facts-and-figures

70. United Nations Economic and Social Affairs. The World's Women 2015, Trends and Statistics. 2015. Retrieved from https://unstats.un.org/unsd/ gender/worldswomen.html

71. Victoria Sexual Assault Centre. What is Sexualized Violence? 2014. Retrieved from https://vsac.ca/sexualized-violence/

72. Velu AV, van Beukering MDM, Schaafsma FG, Frings-Dresen MHW, Mol BWJ, van der Post JAM, Kok M. Barriers and facilitators for the use of a medical mobile app to prevent work-related risks in pregnancy: A qualitative analysis. JMIR Res Protoc. 2017;6(8):e163.

73. Wong DJ, Jones E, Rubin GJ. Mobile text alerts are an effective way of communicating emergency information to adolescents: Results from focus groups with 12- to 18-year-olds. J Conting Crisis Manag. 2018;26(1):183-92.

74. White D, McMillan L. Innovating the problem away? A critical study of anti-rape technologies. Violence Against Women. 2019:1077801219856115.

75. World Health Organization. World report on violence and health. 2002. Retrieved from https://www.who.int/violence_injury_prevention/viole nce/world_report/en/

76. World Health Organization. Violence against women. 2021. Retrieved from https://www.who.int/health-topics/violence-against-women\#tab= tab_1, http://www.who.int/news-room/fact-sheets/detail/violence-again st-women

77. Zaidi AU, Fernando S, Ammar N. An exploratory study of the impact of information communication technology (ICT) or computer mediated communication (CMC) on the level of violence and access to service among intimate partner violence (IPV) survivors in Canada. Technol Soc. 2015;41:91-7

78. Zinzow HM, Resnick HS, Amstadter AB, McCauley JL, Ruggiero KJ, Kilpatrick DG. Drug- or alcohol-facilitated, incapacitated, and forcible rape in relationship to mental health among a national sample of women. J Interpers Violence. 2010;25(12):2217-36.

\section{Publisher's Note}

Springer Nature remains neutral with regard to jurisdictional claims in published maps and institutional affiliations.
Ready to submit your research? Choose BMC and benefit from:

- fast, convenient online submission

- thorough peer review by experienced researchers in your field

- rapid publication on acceptance

- support for research data, including large and complex data types

- gold Open Access which fosters wider collaboration and increased citations

- maximum visibility for your research: over $100 \mathrm{M}$ website views per year

At BMC, research is always in progress.

Learn more biomedcentral.com/submissions 